\title{
SEXUALIDADE E DIVERSIDADE SEXUAL NA FORMAÇÃO EM PSICOLOGIA
}

\author{
Ana Cláudia Bortolozzi Maia'; Marcela Pastana² \\ SEXUALITY AND SEXUAL DIVERSITY IN THE FORMATION IN PSYCHOLOGY \\ LA SEXUALIDAD Y DIVERSIDAD SEXUAL EN LA FORMACIÓN EN PSICOLOGÍA
}

\begin{abstract}
Resumo: Trata-se de uma discussão teórica sobre os temas sexualidade e diversidade na formação em Psicologia, a partir de três pontos fundamentais: I) A sexualidade como uma construção histórica, 2) A Psicologia frente à normatividade e ao preconceito e o Código de Ética Profissional e; 3) A formação em Psicologia e a diversidade sexual. Conclui-se que, apesar do reconhecimento do direito à sexualidade com uma expressão múltipla e diversa, concepções normativas e preconceituosas ainda imperam em senso comum e também na prática de psicólogos; por isso a necessidade em se investir na formação desses profissionais que deveriam, por princípio, respeitar e defender o direito à sexualidade plural.
\end{abstract}

Palavras-chave: Sexualidade. Diversidade Sexual. Formação. Psicologia.

\begin{abstract}
This article presents a theoretical discussion about the theme of sexuality and diversity in the area of formation in Psychology, based on three fundamental issues: I) Sexuality as a historical construction, 2) Psychology facing the normativity and the prejudice and The Professional Ethics Code and 3) The formation in Psychology and the sexual diversity. It is concluded that, in spite of the recognition of the right to sexuality with a multiple and diverse expression, many normative and discriminative conceptions still predominate in the common sense and also in the practice of psychologists, so there is the need to invest in the formation of those professionals that should, as a principle, respect and defend the right to a plural sexuality.
\end{abstract}

Keywords: Sexuality. Sexual diversity. Formation. Psychology.

Resumén: En este trabajo se presenta una discusión teórica sobre el tema de la sexualidad y la diversidad en la formación en Psicología y analiza tres puntos fundamentales: I) La sexualidad como un fenómeno histórico, 2) La Psicología delante de la normatividad y los prejuicios y el Código de Ética Profesional y 3) La formación en Psicología y la diversidad sexual. Se concluyó que a pesar del reconocimiento del derecho a la expresión sexual múltiples y diversas, concepciones normativas y los prejuicios siguen existiendo en el sentido común y también en la práctica de los psicólogos, por lo que hay la necesidad de invertir en la formación de estos profesionales que que deben, por principio, respetar y defender el derecho a la sexualidad plural.

Palabras clave: La sexualidad. Diversidad sexual. Formación. Psicología

\section{Introdução}

Na formação em Psicologia, é fundamental o reconhecimento da importância de uma discussão aprofundada sobre o tema da sexualidade. As ações formativas deveriam somar esforços para que a diversidade das sexualidades pudesse ser respeitada, o que torna necessário questionar: o que, de fato, tem sido feito para diminuir

\footnotetext{
I Psicóloga. Doutora em Educação. Líder do Grupo Sexualidade, Educação e Cultura (GEPESEC). Coordenadora do Laboratório de Ensino e Pesquisa em Sexualidade Humana (LASEX). Docente do Curso de Psicologia da Universidade Estadual Paulista júlio de Mesquita Filho (UNESP), Campus de Araraquara/SP e Campus de Bauru/SP. E-mail: aclaudia@fc.unesp.br; http://lattes.cnpq.br/04|8I87005680I25

2 Psicóloga. Mestre e doutoranda em Educação Escolar na Universidade Estadual Paulista Júlio de Mesquita Filho (UNESP), Araraquara/SP. Membro pesquisador do Grupo Sexualidade, Educação e Cultura (GEPESEC). Docente no Curso de Psicologia do Instituto Municipal de Ensino Superior de São Manuel “Prof. Dr. Aldo Castaldi” (IMES), São Manuel/SP. E-mail: marcelapas@gmail.com; http://lattes.cnpq.br/I295865057468530
} 
a discriminação e o preconceito em relação às múltiplas formas de expressão da sexualidade? Como a formação leva o aluno ou profissional a compreender os vínculos essenciais entre as formas individuais de expressão do desejo e as formas pelas quais a sociedade coage e estimula sua satisfação? Como os muitos preconceitos que se manifestam nos indivíduos se relacionam com aquilo que, por meio de uma construção social e histórica, se consolidou como um conjunto de diferenças, e como essa questão é compreendida e debatida durante a formação?

A categoria profissional dos psicólogos expressou, em seu último código de ética, normas que se opõem a toda forma de discriminação, violência, opressão e exploração, explicitando a posição política da categoria em relação a várias questões, em especial quanto à discriminação de homossexuais, quanto à violência em relação a mulheres e crianças, entre outras questões. Mas é preciso reconhecer que a formação em Psicologia nem sempre dá condições para que os valores que subjazem a essas normas sejam refletidos.

$\mathrm{Na}$ maior parte das vezes, na universidade, essa discussão se restringe a conteúdos específicos de algumas disciplinas, mas o que parece ser mais produtivo é orientar de forma mais geral a formação em uma direção crítica. Nesse sentido, a construção social das diferenças precisa ser compreendida nas mediações entre a sociedade e o indivíduo, pois é nele que se consolidam formas de reação àquilo que se considera diferente, que mantêm e justificam essas construções sociais. Seria necessário que a graduação acadêmica proporcionasse condições para que os alunos refletissem sobre algumas dificuldades e contradições sociais e históricas nessa temática, inclusive percebendo sobre os próprios preconceitos.

O campo da sexualidade é um foro privilegiado para discutir criticamente questões como a discriminação e o preconceito, pois envolve a articulação entre a vida pública e a vida privada. Ao mesmo tempo em que estão envolvidos valores, conceitos, padrões e regras que se constituem em determinado contexto social e histórico, também estão envolvidos elementos subjetivos como as fantasias e o desejo. A formação do psicólogo fornece subsídios para que essa relação seja pensada, tornando possível uma compreensão mais abrangente sobre a dinâmica entre sexualidade e poder, desejo e violência, entre o individual e o social.

É importante que na formação em Psicologia a discussão sobre a construção social das diferenças esteja relacionada com o exercício de reflexão, o movimento de olhar para si, de se colocar em questão, de reconhecer como as normas vigentes em nossa sociedade permeiam a educação de todos, inclusive daqueles que se propõem a pensar criticamente sobre elas e problematizar e questionar o preconceito e a discriminação que tais normas alimentam. É preciso se debruçar sobre os temas com um olhar crítico, buscando entender a organização social em que esses elementos são gerados e fortalecidos, reconhecendo sempre que, por sermos frutos dessa mesma sociedade, estamos necessariamente inseridos e envolvidos com as questões que discutimos. É necessário avaliar de que forma estereótipos e preconceitos foram aprendidos e apreendidos, muitas vezes, tomados como fenômenos naturais, para que sejam buscadas condições de, nas práticas realizadas, tais preconceitos não serem reproduzidos e reiterados (JUNQUEIRA, 2009; KAWATA; NAKAIA; FIGUEIRÓ, 20I0; KEHL, 2002; LOURO, 1996; MAIA, 2009).

A formação em Psicologia pode proporcionar reflexões que desestabilizem a crença em uma verdade imutável, universal, a-histórica e neutra, que cristaliza as formas de se viver a sexualidade, como se fosse um fenômeno natural e inquestionável (RIOS; PORCHAT; TEIXEIRA FILHO, 20I I). Diante dessas considerações, três pontos centrais para a discussão sobre a sexualidade e a diversidade na formação e na atuação de psicólogos serão apresentados.

\section{A sexualidade como uma construção histórica}

O conceito de sexualidade é cultural e histórico. A sexualidade "sadia" ou "moralmente decente" depende de concepções biológicas, médicas, sociais, educacionais, religiosas e morais construídas em diferentes culturas e momentos históricos. Muitos comportamentos sexuais já foram considerados "normais" ou "anormais" dependendo do contexto em que eles foram julgados. É necessário, então, adotar uma perspectiva histórica para compreender que nossos hábitos e nossa moral não são necessariamente os únicos válidos (CHAUÍ, 1985; USSEL, 198I).

As práticas sexuais entre pessoas do mesmo sexo sempre existiram em diferentes sociedades e culturas, embora o conceito de homossexualidade seja muito recente. A homossexualidade, assim como a heterossexualidade, são convenções sociais que, na modernidade, foram elaboradas e justificadas principalmente a partir de construções científicas que conceberam, nomearam e estudaram as práticas homoeróticas; essas práticas não eram novidade, mas o julgamento sobre elas como práticas pecaminosas, sendo crime ou perversão, é um fenômeno mais atual. Segundo Castañeda (2007, p. 23):

A identidade homossexual é um fenômeno relativamente recente. Antes do século XIX, havia práticas homoeróticas (mais ou menos toleradas em diferentes sociedades), mas não pessoas homossexuais. Aqueles que tinham práticas homoeróticas não eram considerados seres à parte, nem por eles mesmos nem pela sociedade: não se concebia a existência de uma identidade fundamentalmente diferente. Isso 
mudou na era moderna, com a penalização da homossexualidade pelos Estados e sua patologização pelos médicos. Assim, apareceu pela primeira vez a figura do homossexual, cuja identidade essencial está definida pelo seu comportamento sexual.

$\mathrm{Na}$ cultura ocidental, marcada pela influência da religião judaico-cristã, condena-se, há muito tempo, todo comportamento não reprodutivo, como por exemplo, a pederastia. A homossexualidade foi severamente punida por se considerar bom somente o sexo realizado dentro do casamento e voltado à reprodução. A partir da modernidade, a ciência juntamente com a religião, classificou e patologizou comportamentos sexuais, tidos como desviantes e pervertidos e a homossexualidade, antes chamada de homossexualismo, passou a representar estigmas de degeneração e imoralidade (CHAUI, 1985; COSTA, 1995; KATZ, 1996; NAPHY, 2004; SPENCER, 1996).

A década de 1970 foi marcada por fatos importantes como a retirada da homossexualidade do rol de doenças e patologia dos regulamentos médicos, como - Manual de Diagnóstico e Estatístico de Perturbações Mentais $^{3}$ e o Classificação Estatística Internacional de Doenças e Problemas Relacionados com a Saúde (CID-I0), de acordo com Castañeda (2007) e Farias e Maia (2009). Jurandir Freire Costa (1995, p. 256) nos diz que:

Homossexualidade e heterossexualidade são identidades sócio-culturais como quaisquer outras e não marca uma 'lei universal da diferença de sexos', inscrita no coração dos homens. Foram construídas pelas ideologias médicas e podem ser desconstruídas por outras teorias. $\bigcirc$ que as mantém em cartaz não são as leis do inconsciente, é nosso vocabulário moral. $\mathrm{E}$ se esse vocabulário estigmatiza, discrimina e faz mal a quem é discriminado, não vejo por que mantê-lo na ordem do dia.

Considerando o termo "homossexual", excessivamente comprometido com o contexto médico-legal, psiquiátrico, sexológico e higienista de onde surgiu, Costa (1995) propõe a utilização de "homoerotismo", como uma noção mais flexível e que descreve melhor a pluralidade das práticas e desejos. Segundo o autor, o termo tomado de um psicanalista chamado Ferenczi exclui a alusão à doença, ao desvio, à anormalidade, à perversão e nega a ideia de que existe algo como uma "substância homossexual", não possuindo a forma substantiva que indica uma identidade.

Muitas pessoas ainda reproduzem concepções de homossexualidade vinculadas à ideia de enfermidade resultando em nossa sociedade manifestações de preconceito, intolerância e homofobia. A homofobia é um termo usado geralmente em referência a um conjunto de emoções negativas: aversão, desprezo, ódio, desconfiança, desconforto e medo, que se vinculam ao preconceito e aos mecanismos de discriminação e violência contra pessoas homossexuais, bissexuais, transexuais, travestis etc. Junqueira $(2009$, p. 375$)$ ressalta a importância de pensarmos a homofobia para além destes aspectos de ordem emocional, como discute no trecho a seguir:

É preciso [...] considerar a existência de um variado e dinâmico arsenal de normas, injunções disciplinadoras e disposições de controle voltadas a estabelecer e a determinar padrões e imposições normalizantes no que concerne a corpo, gênero, sexualidade e o que lhe diz respeito, direta ou indiretamente. [...] Ela [a homofobia], inclusive, diz respeito a valores, mecanismos de exclusão, disposições e estruturas hierarquizantes, relações de poder, sistemas de crenças e de representação, padrões relacionais e identitários, todos voltados a naturalizar, impor, sancionar e legitimar uma única sequência sexo-gênero-sexualidade centrada na heterossexualidade e rigorosamente regulada pelas normas de gênero.

Os padrões definidores de normalidade se fundamentam em uma lógica binária, restringindo a sexualidade a dois polos, deixando de lado tudo o que é "estranho" (LOURO, 2007). E, a partir dessa crença dualista e determinista, reproduzimos uma educação também excludente, que restringe violentamente as manifestações eróticas consideradas "diferentes" e "desviantes" (MAIA; MAIA, 2009). Entende-se por heteronormatividade a presença em inúmeros meios de valores, crenças e ideias que tanto afirmam positivamente o vínculo heterossexual como negam a existência ou o valor dos vínculos homossexuais. Com isso, as situações em que existem variações da orientação sexual heterossexual são ignoradas ou condenadas a partir de crenças sociais, políticas, religiosas ou culturais. A heteronormatividade representa um modo de compreender o mundo em que a única forma considerada "normal" de expressão do desejo sexual seria a heterossexualidade (JUNQUEIRA, 2009; LOURO, 2007; MISKOLCI, 20I2).

Miskolci (2012), ao discutir a heteronormatividade destaca que o conjunto de prescrições que fundamenta processos sociais de regulação e controle não atinge somente aqueles que são descritos como desviantes e anormais; os ideais normativos não são repressores apenas para os que não se sentem atraídos pelo sexo oposto, e sim, o modelo imposto de gênero e sexualidade supostamente coerente, superior e "natural" é inalcançável e opressor para todos.

Deve fazer parte da formação em Psicologia a reflexão e a discussão sobre esses modelos, assim como sobre as contradições relacionadas às normas e padrões

3 Tradução para o português do original Diagnostic and Statistical Manual of Mental Disorders. 
sociais, e também sobre a forma como são consubstanciadas nas subjetividades, nos sentimentos, ideias, memórias e aspirações dos sujeitos, desenvolvendo uma crítica abrangente e profunda da dificuldade em formar-se como um indivíduo em nossa sociedade. De outro modo reproduz-se, impensadamente ou não, esses padrões, que são modelados pela cultura desde a educação oferecida na família, na escola e também nos meios de comunicação. No entanto, a formação em Psicologia precisa ser pensada como uma educação sexual formal, como uma proposta intencional de educar em sexualidade, e não pode ser aceitável um viés heteronormativo, ou a mera reprodução de modelos. É preciso investir em processos de formação em cursos de graduação que esclareçam sobre os valores sociais e a construção cultural da sexualidade. É preciso desconstruir determinismos naturalistas, estimulando a reflexão de que o que somos em relação à nossa sexualidade é uma construção subjetiva, mas também social.

\section{A Psicologia frente à normatividade $e$ ao preconcei- to: o Código de Ética Profissional e a Resolução $n^{\circ}$ 00I/1999}

A defesa dos direitos humanos e a busca pela consolidação de políticas públicas são elementos que orientam a ação do Sistema de Conselhos de Psicologia. Dentre os compromissos assumidos estão o enfrentamento a toda forma de preconceito e o fortalecimento de práticas psicológicas baseadas na inclusão e no respeito às diferenças (CECARELI; KAHHALE; OLIVEIRA, 20 I I; UZIEL, 20I I).

Em 1999, foi aprovada pelo Conselho Federal de Psicologia a resolução $n^{\circ} 001 / 1999$, que prevê que a atuação profissional não deve abordar a homossexualidade como patologia, distúrbio ou perversão, mas como uma das muitas formas de expressões possíveis das sexualidades. Mais do que não abordar como doença, é apontada como compromisso dos profissionais da Psicologia a contribuição para a reflexão sobre o preconceito e a busca pelo combate e a desconstrução de discriminações e estigmatizações.

Essa resolução baseia-se tanto numa dimensão teórica quanto numa dimensão ética: quanto à primeira, o fundamento está no princípio de que a homossexualidade não se constitui uma doença, um distúrbio ou uma perversão e, portanto, não deve ser "tratada" com promessas de cura ou reversão; quanto à segunda, está no dever de trabalhar para que todas as formas de violência, discriminação, negligência e exploração sejam suprimidas.

Considerando [...] que a forma como cada um vive sua sexualidade faz parte da identidade do sujeito, a qual deve ser compreendida na sua totalidade e [...] a homossexualidade não constitui doença, nem distúrbio e nem perversão, [...] que há, na sociedade, uma in- quietação em torno de práticas sexuais desviantes da norma estabelecida sócio-culturalmente [O CFP] Resolve: Art. $1^{\circ}$ Os psicólogos atuarão segundo os princípios éticos da profissão notadamente aqueles que disciplinam a não-discriminação e a promoção e bem-estar das pessoas e da humanidade. Art. $2^{\circ}$ Os psicólogos deverão contribuir, com seu conhecimento, para uma reflexão sobre o preconceito e o desaparecimento de discriminações e estigmatizações contra aqueles comportamentos ou práticas homoeróticas. Art. $3^{\circ}$ Os psicólogos não exercerão qualquer ação que favoreça a patologização de comportamentos ou práticas homoeróticas, nem adotarão ação coercitiva tendente a orientar homossexuais para tratamentos não solicitados. Parágrafo Único - Os psicólogos não colaborarão com eventos e serviços que proponham tratamento e cura das homossexualidades. Art. $4^{\circ}$ Os psicólogos não se pronunciarão, nem participarão de pronunciamentos públicos, nos meios de comunicação de massa, de modo a reforçar os preconceitos sociais existentes em relação aos homossexuais como portadores de qualquer desordem psíquica (CONSELHO FEDERAL DE PSICOLOGIA, 1999).

Apresentar e discutir sobre as normas presentes no código de ética na formação em Psicologia não se refere a apresentá-la de forma dogmática ou relativista, mas sim, visando propiciar uma relação reflexiva, que vise o desenvolvimento da autonomia. Essa resolução, que se coloca ao lado de outras demandas atuais da sociedade, destaca a necessidade de que os profissionais reflitam sobre sua formação e sobre suas práticas, pois também no campo das teorias e práticas há a necessidade de rever pressupostos, analisar ações costumeiras e investigar as consequências da adoção de novos postulados. Alguns deles se tornam ultrapassados pela própria dinâmica social, pela emergência de novas forças políticas e novos sujeitos.

Desde a criação da Resolução, há mais de 10 anos, muitos psicólogos a comemoram como um avanço social do Conselho, outros se informaram e estudaram o tema, reconhecendo sua pertinência, mas também existiram aqueles que, por diversas razões, mostraram-se intolerantes e muito resistentes em modificar suas concepções ou sua prática. Nesse sentido, torna-se importante considerar as questões: o que mudou na formação e na atuação dos psicólogos desde a Resolução? O que psicólogos e outros profissionais sabem ou pensam sobre essa resolução e sobre a temática da sexualidade e da homossexualidade? $O$ que se pode fazer durante a formação para ampliar essa compreensão e desenvolver o respeito à diversidade? Estudos e pesquisas a esse respeito no Brasil são raros, talvez porque o registro das atitudes e concepções dos psicólogos a esse respeito, antes e depois da Resolução, seria muito abrangente e complexo. Mas seria muito interessante que se pudesse realizar um debate mais amplo e aprofundado sobre a questão. 
A importância da discussão sobre as relações entre a Psicologia e a diversidade sexual e a demarcação do posicionamento crítico da categoria sobre a promoção dos direitos das pessoas Lébiscas, Gays, Bissexuais, Travestis e Transexuais (LGBT) motivou a organização do Seminário Nacional de Psicologia e Diversidade Sexual: desafios para uma sociedade de direitos, ocorrido em 20I0, em Brasília, cujos debates realizados, apoiados na Resolução $n^{\circ} 001 / 99$, foram publicados em 201 I, no livro Psicologia e diversidade sexual: desafios para uma sociedade de direitos. Nesse evento, profissionais da Psicologia como Ana Paula Uziel, Daniela Murta Amaral, Edna Peters, Kahhale, Janne Calhau Mourão, Fernando Silva Teixeira Filho, Luan Carpes Barros Cassal, Luis Felipe Rios, Marcus Vinícius de Oliveira, Patrícia Porchat, Paulo Roberto Ceccarelli, Rosângela Aparecida Talib e Wiliam Siqueira Peres, assim como de outras áreas da ciência, debateram sobre a relação entre a Psicologia e a diversidade sexual. Nesse debate, ressaltou-se a atuação da Psicologia e a promoção de direitos e do exercício pleno da cidadania e a importância de pensar a sexualidade, o gênero e a orientação sexual como construções sociais e históricas, de modo a problematizar a compreensão normativa que engessa a sexualidade em divisões, classificações e hierarquias. Além disso, alertou-se sobre a necessidade de se refletir criticamente sobre a força da heteronormatividade em nossa sociedade e o combate a todas as formas de preconceito, dentre elas, a homofobia.

A expressão da Resolução se insere em um contexto mais amplo, em que se divulgavam afirmações contra ao movimento de patologização de toda forma de expressão sexual que difere da norma e/ou do pensamento hegemônico. A forma como os padrões de normalidade é muitas vezes reforçada pelos discursos médico, psicológico, psiquiátrico, jurídico, acadêmico etc. se reflete em um quadro em que se determina a quem será acessível ou não a cidadania. Assim, outro compromisso estabelecido pelo Conselho Federal, discutido por Paulo Roberto Cecarelli, Edna Kahalle e Marcus Vinicius Oliveira (20I I), no seminário citado acima, seria o engajamento na campanha pela despatologização das identidades trans, já que a transexualidade continua sendo considerada uma doença tanto pelo DSM, quanto pelo CID. Nesse sentido, Marchi, Bento e Peres (201 I, p. 104) ressaltam a importância da promoção de uma Psicologia:

[...] comprometida com a emancipação psicossocial e cultural das pessoas, sem classificação, sem patologização e sem reducionismos teóricos, rompendo de vez com paradigmas binários, universais e essencialistas de manutenção ao sistema sexo/gênero/desejo que tanto impede o direito de ser, estar e circular no mundo das pessoas que não se filiam aos modelos heteronormativos, racistas e misóginos diante da vida.
Muitas pessoas recorrem aos profissionais da Psicologia nos mais diversos âmbitos (clínica, escola, hospitais, meios de comunicação) para buscar ajuda com relação ao sofrimento por se sentir diferentes, desajustadas, inadequadas, desviantes do que é tido como normalidade. É forte a imagem da Psicologia como a "guardiã" dessa normalidade, como se coubesse aos profissionais ajustar, corrigir, buscar em suas intervenções adaptar as pessoas aos modelos do que é tido como positivo e valorizado (KEHL, 2002; MAIA, 2009; OLIVEIRA, 20II). Diante destas considerações, como pensar uma formação em Psicologia que não contribua para a produção e a reprodução de normatividades? Seria imprescindível que nessa formação, os valores, concepções e normas aprendidas e incorporadas no decorrer da educação, sejam pensados e repensados de forma crítica e consciente, para não serem reproduzidos de modo irrefletido. É preciso afinar nossos olhares para reconhecer como, em nossas práticas, podemos reforçar o sofrimento que nos propomos a combater (MAIA, 2009; PAIVA, 2008).

É importante refletir que o psicólogo, geralmente devido à credibilidade e à autoridade conferida à categoria profissional, acaba por assumir um papel prescritivo, oferecendo regras e modelos sobre como as pessoas devem ser, ou ainda oferecer explicações naturalizantes e essencializantes sobre os modos de desejar, sentir prazer e se relacionar; quando deveriam de fato esclarecer, promover a reflexão e lutar pela autonomia dos sujeitos (KEHL, 2002; OLIVEIRA, 20I I). Castañeda (2007) exemplifica a questão, afirmando que frequentemente os psicólogos são consultados para que expliquem as "causas" da ocorrência de homossexualidade pelas mais diversas pessoas: professores, jornalistas, comunidade em geral, e também dos próprios sujeitos que se identificam como homossexuais e suas famílias. Isso, segundo a autora, reflete a dificuldade atual em nossa sociedade em lidar com as diferenças.

Embora haja, de fato, várias tentativas teóricas de explicações para o fenômeno da homossexualidade, não há estudos conclusivos sobre essa questão e nem isso nos parece ser necessário (CASTAÑEDA, 2007; COSTA, 1995; KATZ, 1996). Costa (1995) indica a necessidade de identificar fatores genéticos ou outros que influenciem ou determinem sobre os desejos eróticos. No entanto, a questão mais importante para a qual se deve atentar seria não sobre quais são esses fatores, mas as motivações e interesses em saber sobre eles. Na mesma direção, Weeks (2010) afirma que a principal preocupação não deveria ser com o que causa a homossexualidade ou a heterossexualidade nos indivíduos, mas compreender o que leva a nossa cultura a privilegiar uma forma e marginalizar a outra, atribuindo tanta importância a essa divisão, e por que essa visão gera tanta intolerância, violência, preconceito e discriminação. 


\section{A formação em Psicologia e a diversidade sexual}

A leitura da Resolução no 001/99, do Conselho Federal de Psicologia, leva ao entendimento de que cabe ao psicólogo contribuir para que gays, lésbicas, travestis e transexuais sejam tratados com igualdade e respeito. A orientação sexual faz parte integrante do sujeito e está relacionada à interação de inúmeros fatores psicológicos e sociais. É preciso ressaltar que o sofrimento pelo qual as pessoas com desejos homoeróticos passam decorre em grande medida não da existência destes desejos, mas da relação intolerante da sociedade. $O$ atendimento deve priorizar as dificuldades que enfrenta qualquer pessoa em situação de estigmatização por uma diferença. Em geral, não é o desejo homoerótico que incomoda o sujeito, mas a dificuldade de lidar com este desejo diante de uma sociedade homofóbica, o que ocasiona conflitos familiares e interpessoais diversos. Nesse sentido, independentemente da abordagem teórica em que se baseie o psicólogo em sua atividade profissional, o que se propõe no atendimento de clientes homossexuais não é o "tratamento" da homossexualidade, como se fosse uma "doença curável".

Sousa Filho (20I I) discute que a orientação sexual não se trata de uma essência ou substância, mas sim de uma construção em que se imbricam dimensões sociais, culturais, históricas e pessoais. Sendo uma expressão do desejo, está relacionada a elementos singulares, que abrange prazeres, sensações, fantasias, imaginação, práticas eróticas etc. Mas também não podemos perder de vista a dinâmica entre o subjetivo e o social, sendo a orientação sexual construída permeada de relações de poder em constante vigília sob os padrões, os ideais e os modelos culturais, o que a torna um fenômeno individual tanto quanto coletivo. Não é possível pensarmos a questão da orientação sexual sem pensarmos os padrões de gênero, a história pessoal, as relações familiares, sociais e o contexto da cultura como um todo.

$\mathrm{Na}$ atuação clínica, é preciso compreender o fenômeno da homossexualidade para além do âmbito privado, e embora a discriminação apareça no sofrimento particular do cliente atendido, não podemos perder de vista que ela só existe no contexto social que produz a noção de que esta é uma diferença desvantajosa. Muitas queixas existem em função de relacionamentos interpessoais e processos subjetivos que podem ou não ter a ver com a orientação do desejo do sujeito.

É importante também considerar que o preconceito atinge não só os indivíduos estigmatizados pelo desejo homoerótico, mas também seus familiares. A própria introjeção de certa "culpa", ocorre entre as pessoas que se percebem homossexuais e também seus pais e mães atribuindo o fato de alguém se tornar homossexual a uma falha na educação ou na estrutura familiar. É comum que as famílias busquem os serviços de psicólogos, pedindo explicações ou mesmo tratamentos para reverter e curar a homossexualidade e, nesse sentido, o psicólogo deveria esclarecer e reconhecer que o sofrimento dos familiares está relacionado à falta de referências sobre a diversidade e ao padrão heteronormativo aprendido (CASTAÑEDA, 2007).

Outras questões importantes somariam ao papel do psicólogo, já previsto na Resolução n 00I/99 do Conselho Federal de Psicologia, e merecem ser destacadas: em primeiro lugar, o psicólogo deve atuar como um agente de esclarecimento e reflexão que busque minimizar as situações sociais preconceituosas. A omissão e o silêncio podem contribuir para a reprodução e a legitimação de situações, discursos e práticas excludentes. Além disso, é necessário que o psicólogo, em qualquer atuação, busque colaborar como agente de educação sexual e como mediador em instituições educativas, como a escola e a família. Ao trabalhar, por exemplo, como formador de agentes educativos em projetos de intervenção intencionais em educação sexual, é preciso que o psicólogo discuta e reflita sobre as questões de gênero e diversidade, sobre os preconceitos e estereótipos relacionados à sexualidade e sobre os padrões que são transmitidos e reforçados por meio de uma socialização repressiva. O psicólogo tem um importante papel nos projetos de educação sexual realizados em instituições escolares ou outras, espaços em que pode atuar aprofundando a reflexão necessária e mediando a formação continuada de educadores de crianças e jovens que se propõem a trabalhar intencionalmente com o tema da sexualidade.

Nesse sentido, cabe ao psicólogo considerar a existência da diversidade humana em relação aos padrões afetivos e sexuais, buscando problematizar a reprodução de normas, valores e práticas heteronormativas. Para isso, é importante que a formação em Psicologia propicie momentos em que seja possível refletir sobre essas questões, lembrando que fomos educados em meio a estereótipos sobre a sexualidade em uma socialização tão repressiva que muitas vezes sequer permite a expressão do sofrimento que dela resulta.

A atenção para as múltiplas possibilidades de se expressar desejos, se relacionar e buscar prazer, as novas configurações familiares e amorosas, para o acolhimento e o respeito àqueles que, por não corresponderem aos padrões normativos vigentes, e são vítimas de discriminação violenta, depende que o profissional tenha tido a oportunidade de pensar e repensar sobre os próprios preconceitos, para que possa buscar não reproduzir os padrões normativos de modo explícito ou implícito.

Como parte da autoavaliação permanente, é importante que o psicólogo reflita e questione constantemente os padrões do que é tido culturalmente como normalidade, inclusive aqueles inerentes à própria ciência psicológica e, ao estudar, é preciso sempre estar 
aberto às novas formas de ler e compreender o mundo, às mudanças sociais e, principalmente, é preciso sempre considerar criticamente as crenças, valores e concepções pessoais, pois estas são também fruto de sua história de vida pessoal, na atuação profissional que exerce.

\section{Considerações finais}

$\mathrm{Na}$ educação em geral o padrão da normalidade impõe condições estreitas para a adaptação dos indivíduos, o que gera sofrimento pessoal, discriminação e preconceito, violência física e simbólica. É preciso ficar claro que sempre houve padrões e que, mesmo numa sociedade livre, provavelmente existiriam também formas mais ou menos padronizadas de conduta humana; a questão é como o indivíduo pode se apropriar desses padrões, se ele pode, durante sua formação, refletir sobre esses padrões e sobre suas qualidades ou contradições. Ou a educação ocorre por meio de uma reflexão sobre a sociedade e sobre o próprio sujeito, estimulando tanto a crítica quanto a autocrítica, ou é grande a possibilidade de que a mera ilustração sobre sexualidade resulte em uma ação normativa e repressiva.

A despeito de ampla discussão realizada por muitos autores sobre a diversidade, e de haver um consenso de que as formas de expressão da sexualidade são múltiplas, ainda sobrevivem concepções normativas, estereótipos e preconceitos, presentes no processo de educação sexual e reproduzidos por meio de muitas instituições familiares, sociais e culturais. Essas concepções, infelizmente, existem naqueles que deveriam esclarecer e ampliar o modo de compreender a sexualidade, como é o caso dos psicólogos.

O psicólogo não pode basear a sua atuação somente em convicções pessoais, e as normas da Resolução $n^{\circ}$ 001/99 do Conselho Federal de Psicologia servem como base para uma discussão mais ampla e abrangente sobre a prática profissional. A mera imposição da regra, entretanto, colocaria lenha na fogueira da repressão, dificultando aquilo que é mais necessário: uma formação que privilegie a reflexão, o reconhecimento dos nossos próprios preconceitos e dificuldades relacionados à sexualidade. Não basta a existência de determinada regra, é preciso que aqueles que estão diante dela tenham tempo e possibilidades de refletir sobre o sentido dessas regras, de modo que, ao se apropriarem desses sentidos possam também acatá-las não por meio respeito à instância legal ou por medo das punições, mas por liberdade, por escolha própria, numa ação mais autônoma.

Da mesma forma, uma educação sexual ética é aquela que contribui para desenvolver a capacidade do sujeito de tomar decisões mais autônomas em relação à sua sexualidade, para que, compreendendo o vínculo entre sexualidade, poder, dominação e violência em nossa sociedade possa refletir sobre sua própria história de educação, e construir relações baseadas num mútuo reconhecimento e no respeito às diferenças. Essa educação não pode prescindir do diálogo e da compreensão de que não basta somente criticar os tabus sexuais na sociedade, construídos historicamente em diferentes culturas, é preciso desenvolver uma aguda capacidade de perceber como nosso próprio desejo se constitui mediado por padrões sociais que vinculam a sexualidade e o poder.

A formação em Psicologia deveria, segundo nosso juízo, orientar-se por esses mesmos princípios, e os educadores que promovem essa formação, evidentemente, também tem de refletir sobre si mesmos. Essa discussão precisa ser acompanhada de um debate amplo sobre a formação de psicólogos, principalmente no que diz respeito à sexualidade. A sexualidade não constitui, em muitos casos, uma disciplina específica nos cursos de formação e, além disso, não se trata somente da existência de uma disciplina específica, mas de realizar uma discussão que abarca várias disciplinas, como a ética, a filosofia, a história, a sociologia e, finalmente, a própria Psicologia. $O$ foco dessa discussão seria tanto a violência e a discriminação no campo social como a formação do sujeito preconceituoso; o vínculo histórico entre sexualidade e poder necessitaria ser colocado como pano de fundo, o que permite tomar tais questões também numa perspectiva histórica.

A persistência de atos violentos contra pessoas que destoam dos padrões vigentes evidencia a necessidade urgente de desenvolver pesquisas que compreendam o fenômeno da homofobia a partir da articulação entre indivíduo e cultura. Estas questões deveriam fazer parte do trabalho do psicólogo e de quem precisa e se beneficia de seus serviços. O reconhecimento da multiplicidade de formas de expressão da sexualidade, tema atual e relevante, interessa a todos aqueles que, como profissionais ou não, defendem uma sociedade que respeite a diversidade humana.

\section{Referências}

CASTAÑEDA, M. A experiência homossexual: explicações e conselhos para os homossexuais, suas famílias e seus terapeutas. Trad. B. M. Hervot e F. S. Teixeira Filho. São Paulo: Girafa, 2007.

CECARELLI, P. R.; KAHALLE, E. M. S. P.; OLIVEIRA, M. V. Enfrentamento à patologização e à homofobia: Código de Ética do Psicólogo e Resolução CFP 00I/1999. In: CONSELHO FEDERAL DE PSICOLOGIA. Psicologia e diversidade sexual: desafios para uma sociedade de direitos. Brasília: CFP, 20I I. p. 229-237. 
CHAUÍ, M. Repressão sexual: essa nossa (des) conhecida. 8. ed. São Paulo: Brasiliense, 1985.

\section{CONSELHO FEDERAL DE PSICOLOGIA} Resolução $n^{\circ}$ 001/99. Disponível em: <https:// site.cfp.org.br/wp-content/uploads/ 1999/03/ resolucaol999_I.pdf >. Acesso em: 25 set. 2006.

CONSELHO FEDERAL DE PSICOLOGIA. Código de ética profissional do psicólogo. Brasília: CFP, 2005.

COSTA, J. F. A face e o verso: estudos sobre o homoerotismo II. São Paulo: Escuta, 1995.

FARIAS, M. O.; MAIA, A. C. B. Adoção por homossexuais: a família homoparental sob o olhar da Psicologia Jurídica. Curitiba: Juruá, 2009.

JUNQUEIRA, R. D. Homofobia nas escolas: um problema de todos. In: JUNQUEIRA, R. D. (Org.). Diversidade sexual na educação: problematizações sobre a homofobia nas escolas. Brasília: MEC/SECAD; UNESCO, 2009. p. I3-5I. (Coleção Educação para Todos)

KATZ, J. N. A invenção da heterossexualidade. Rio de Janeiro: Ediouro Publicações, 1996.

KAWATA, H. O.; NAKAYA, K. M.; FIGUEIRÓ, M. N. Reeducação sexual: percurso indispensável na formação do/a educador/a. Revista Linhas, v. I I, n. I, p. 85-III, 2010.

KEHL, M. R. Sobre ética e psicanálise. São Paulo: Companhia das Letras, 2002.

LOURO, G. L. Gênero, sexualidade e educação: uma perspectiva pós-estruturalista. 5. ed. Petrópolis, RJ: Vozes, 1996.

LOURO, G. L. Currículo, gênero e sexualidade - o "normal', o "diferente" e o "excêntrico". In: LOURO, G. L. et al. (Org.). Corpo, gênero e sexualidade: um debate contemporâneo na educação. 3. ed. Petrópolis, RJ: Vozes, 2007. p. $4 \mid-52$.

MAIA, A. C. B.; MAIA, A. F. Educação para as questões de gênero e diversidade sexual. In: MORAES, M. S. S.; MARANHE, E. A. (Org.). Educação na diversidade e cidadania. Bauru, SP: Unesp; Brasília: MEC/SECAD, 2009. v. 4.

MAIA, A. C. B. Sexualidade, deficiência e gênero: reflexões sobre padrões definidores de normalidade. In: JUNQUEIRA, R. D. (Org.). Diversidade sexual na educação: problematizações sobre homofobia nas escolas. Brasília: Ministério da Educação/SECAD; UNESCO, 2009. p. 265292. (Coleção Educação para Todos)

MARCHI, M.; BENTO, B.; PERES, W. S. Desnaturalização das questões de gênero. In CONSELHO FEDERAL DE PSICOLOGIA. Psicologia e diversidade sexual: desafios para uma sociedade de direitos. Brasília: CFP, 20II. p. 67- 105.

MISKOLCI, R. Teoria Queer: um aprendizado pelas diferenças. Belo Horizonte: Autêntica, 2012.

NAPHY, W. Born to be gay: História da homossexualidade. Lisboa: Edições 70, 2004.

PAIVA, V. A psicologia redescobrirá a sexualidade? Psicologia em Estudo, v. 13, n. 4, p. 64 I-65I, 2008.

RIOS, L. F.; PORCHAT, P.; TEIXEIRA FILHO, F. $S$. A prática psicológica e a sexualidade como categoria de subjetivação. In: CONSELHO FEDERAL DE PSICOLOGIA. Psicologia e diversidade sexual: desafios para uma sociedade de direitos. Brasília: CFP, 20I I. p. 25-65.

SPENCER, C. Homossexualidade: uma história. Rio de Janeiro: Record, 1996.

SOUSA FILHO, A. Orientação sexual: construção política do desejo, ou crítica da substancialização. In: GUIMARÃES, V. M. G.; IVANILDA, M. G.; ZENAIDE, M. N. T. Gênero, diversidade sexual e educação: conceituação e práticas de direito e políticas públicas. João Pessoa: Ed. UFPB. $201 \mathrm{I}$. p. 79-92.

USSEL, J. Repressão Sexual. Rio de Janeiro: Campus, I98I.

UZIEL, A. P. Diversidade Sexual, democracia e promoção de direitos. In: CONSELHO FEDERAL DE PSICOLOGIA. Psicologia e diversidade sexual: desafios para uma sociedade de direitos. Brasília: CFP, 20II. p. II-24.

WEEKS, J. O corpo e a sexualidade. In: LOURO, G. L. (Org.). O corpo educado: pedagogias da sexualidade. Belo Horizonte: Autêntica, 2010. p. 35-82. 